\title{
Balanced relationships: management of client-supplier relationships in product development
}

\author{
P.M. Wognum ${ }^{\text {a,* }}$, Olaf A.M. Fisscher ${ }^{\mathrm{a}}$, Suzanne A.J. Weenink ${ }^{\mathrm{b}}$ \\ ${ }^{a}$ University of Twente, Faculty of Technology and Management, Department of Technology and Organisation, P.O. Box 217, 7500 AE \\ Enschede, The Netherlands \\ ${ }^{b}$ Polynorm Automotive BV, Bunschoten, The Netherlands
}

Received 14 October 2000; received in revised form 28 February 2001; accepted 15 March 2001

\begin{abstract}
In strongly competing markets, such as the automotive industry, collaboration between clients (e.g., OEM) and suppliers is changing. Ford and Chrysler are examples of companies that no longer consider suppliers as mere component producers, but as partners in the creation of innovative products. Clients outsource not only production of parts to suppliers, but also the development of parts and increasingly the development of complete (sub)systems. Collaboration in product development between client and supplier is becoming more and more important.

Management of collaboration is, however, extremely complex given the number of unsuccessful collaborative efforts. Apparently, problems in managing collaboration are different from the problems managers are used to encountering. However, little is known yet about the problems in collaborative projects between clients and suppliers.

In this paper, a number of problems in collaborative projects will be identified. The paper is based on case studies in three Dutch companies involved in changing client-supplier relationships. (ㅇ 2002 Elsevier Science Ltd. All rights reserved.
\end{abstract}

Keywords: Client-supplier relationships; Collaborative design; Organisational change

\section{Introduction}

Collaborative product development forms an answer to the market demands that are changing due to globalisation of competition and individualisation of consumer wishes. Today, consumers expect a varied assortment of innovative and highly qualified products. Moreover, client organisations are forced to develop and produce these products in limited time against low costs to stay ahead of competition.

However, companies have increasingly less time, fewer people, and less financial means to satisfy the market demands alone. Extensive collaboration with suppliers offers companies possibilities to gain fast access to specialist knowledge and capabilities, to spread and share costs and risks, and to better exploit the expertise

* Corresponding author. Tel.: +31-534893736/3480; fax: +31534892159 .

E-mail address: p.m.wognum@sms.utwente.nl (P.M. Wognum). of their partners (Douma, 1997; Quinn and Hilmer, 1994; Littler et al., 1995).

Close collaboration between client and supplier fits the 'lean-production' approach (Womack et al., 1990). In this approach, the product creation process as a whole is considered, instead of each of the companies that perform a part of this process (Lamming, 1996). Each activity that is executed at a client or at a supplier on behalf of the product to be created contributes to the success of that product. To achieve success collaboration is essential.

Management of collaboration is highly complex. Research has shown that more than $50 \%$ of the collaborative efforts are unsuccessful (Harrigan, 1985; Littler et al., 1995). Apparently, managers meet problems that are different from the ones they are used to. Until now, little is known yet of the problems managers of collaboration between clients and suppliers in product development may encounter.

Much is written about the perceived advantages of collaboration. In addition, much attention is devoted to the support information and communication technology 
(ICT) may provide to collaborative product development between geographically dispersed sites. In this paper, these issues will be addressed too. However, the main focus will be on problem areas in management of collaborative product development between client and supplier.

The research reported in this paper can be characterised as empirical research. Information has been gathered to gain insight into recurring problems and the organisational changes necessary to solve them. The research consisted of two steps. A first impression of the new strategy has been developed based on interviews with managers and product development engineers at Lockheed Martin, Ford, Chrysler, and General Motors in the United States of America. Second, three Dutch companies have been visited to further investigate the consequences of collaboration in product development for daily practice. In this step, semi-structured interviews have been held with managers, project leaders, product development engineers, and purchase and sales managers. They have been asked about their experience with realising the changes in the product development strategy. The second research step is reported on in this paper.

\section{Management of collaboration in product development}

Compared to the situation a number of years ago, the role of suppliers seems to change to a large extent. Based on the literature and our first explorations in the USA, the most important changes will be described below.

\section{Increased added value}

Suppliers change from merely producing parts ('jobbers') to also developing them. In this way, the added value of products delivered to clients increases. At the same time, clients started to request their suppliers to deliver not only parts but complete (sub)systems, which have even larger added value.

2. Longer-lasting collaborative relationships

Traditionally, one-year or two-year contracts are needed for the production and delivery of parts. After the contract has finished, negotiation with suppliers is needed again for each new contract. In this way, it is possible that more than one supplier is involved in the production of a part during the lifecycle of a product. In collaborative product development collaborative relationships last longer. Firstly, suppliers are involved in a new product development project already during the design phase. Secondly, suppliers cannot be replaced easily due to the complexity of the order. As a consequence, collaborative relationships are built for the duration of the lifecycle of a product.

\section{Larger mutual dependency}

Since the production of parts according to client specifications is relatively simple, the number of suppliers in this category (jobbers) is fairly large. Jobbers strongly depend on their client. Conversely, the client has a strong power position over its jobbers. By contrast, since suppliers can offer greater added value and longer-term collaborative relationships are built the client has become more dependent on the knowledge, continuity, and care of the selected suppliers. As such, in the new strategy, clients and suppliers have become more mutually dependent.

The changes mentioned above have large consequences for the collaborative relationship between parties. Traditionally, in cases of asymmetric balance of power the most powerful party, often the client, imposes requirements to the other party [see Fig. 1(a)]. In the new strategy, because of increasing equivalence, both parties can attach conditions to the collaboration. Management of collaboration no longer means that one party tries to use, influence, or control the other party, but, instead, that the relationship between client and supplier is the central aspect [see Fig. 1(b)] (Lamming, 1996). To an increasing extent, a win-win situation for both parties will be pursued.

The changing client-supplier relationship, as described in the literature, concerns for a large part the automotive industry (see e.g., Womack et al., 1990; Helper, 1991). For example, Helper distinguishes two types of relationships. In the so-called 'exit' relationship a client organisation having a problem with its supplier searches for a new supplier. By contrast, in a 'voice' relationship, a client collaborates with its supplier to try to solve the problems. Based on research, Helper has characterised the client-supplier relationships before

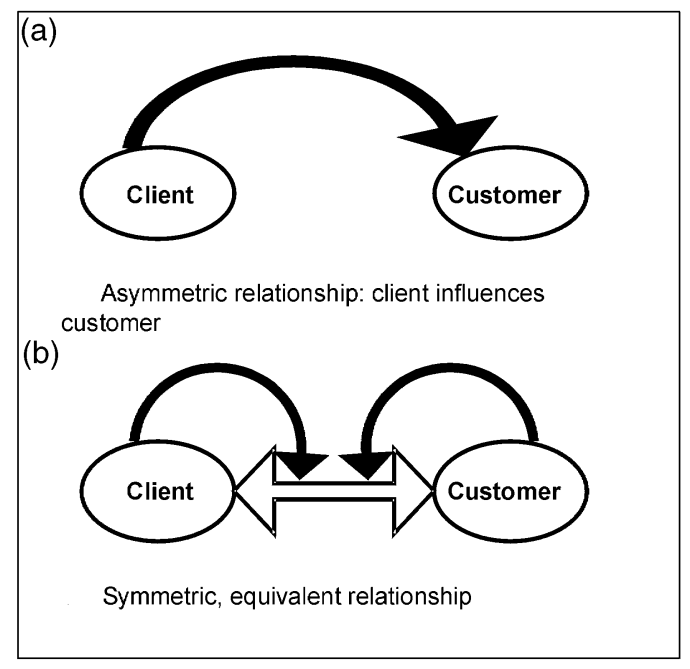

Fig. 1. Differences in client-supplier relationships. 
1980 as primarily 'exit'-based. After 1980, car manufacturers have increasingly built long-term relationships, in particular when Japanese car manufacturers, like Toyota, showed that skilled suppliers may contribute to improving their competitive position.

Collaboration in product development increases the necessity for mutual alignment and communication between client and supplier. Alignment concerns many factors of both client and supplier organisations, like goals at several levels, processes, machines, methods, tools, people skills and experiences, people attitudes, organisational arrangements, like task definition, roles, responsibility and authority, and culture. Communication strongly depends on the degree of alignment and, conversely, helps to shape alignment (see e.g., Wognum and Faber, 1999a,b).

Large differences between client and supplier organisations or lack of understanding of these differences may lead to difficult or even impossible collaboration. Employees involved in collaborative projects may encounter these differences since they have to deal with multiple organisational contexts: the context of their mother organisation, the context of the partner organisation, and the context of the project organisation. Too large a difference between contexts may lead to, e.g., a difference in expectations, time loss because of people waiting for each other, and communication problems. For example, expectations may differ because people are used to different ways of working and may be unaware of the differences or communication problems may occur because of interoperability of communication tools or differences in information standards.

Collaboration, in terms of alignment and communication, depends on understanding the differences and the level of alignment of the organisations involved. In other words, the relationship between client and supplier needs to be managed. In the remainder of this paper, experiences of managers, project leaders, and engineers with the execution of this task will be described. These experiences have been collected through company visits to three Dutch companies (Weenink, 1999). These companies will be briefly introduced below.

\section{Short introduction to the companies visited}

The companies that have been visited as part of the second research step are Océ technologies, NedCar Product Design \& Engineering and Polynorm Automotive.

1. Océ Technologies designs and produces copying machines for the professional (international) market. Of all parts $80 \%$ is purchased. The remaining $20 \%$ consist of strategic components like toners. These are produced at Océ. At the start of the development of a colour copier in 1994, Océ started to outsource the development of several subsystems to suppliers.

2. NedCar Product Design \& Engineering designs and produces cars for its shareholders Mitsubishi and Volvo. As an example of the collaboration, the Mitsubishi Carisma and the Volvo X40 are produced on the same production line. The collaboration between Volvo and Mitsubishi started in 1992. Since then, NedCar has structurally outsourced a larger part of product development activities to suppliers.

3. Polynorm Automotive is a first-tier supplier of body parts like doors and roofs for the car industry. Traditionally, Polynorm Automotive is a supplier of production capability. Since two years, however, Polynorm Automotive structurally focuses on long-term orders by developing and producing specific parts during the total lifecycle of a car.

\section{Daily practice of collaboration is changing}

Collaboration in product development changes the role of supplier and client in the product development process. As stressed before, the relationship between client and supplier is changing accordingly. Client and supplier become more and more mutually dependent. The relationship becomes, hence, more equivalent and less hierarchical. In the following section the new (strategic) roles of client and supplier will be described. After that, changes in searching and selecting partners and changes in executing collaborative projects will be described.

\subsection{New role of supplier}

Océ, NedCar, and other client organisations ask suppliers to become strategic partners. This means that suppliers not only produce parts (jobber) but are also responsible for the design of parts. Supplier Polynorm has a slightly different role. The design of body parts is not outsourced to Polynorm, but the design of the tooling required to manufacture the parts is. Car manufacturers keep on designing the body parts themselves, because car design is one of the most important characteristics for consumers buying a car.

In addition, Océ, NedCar, and other clients are searching for suppliers that can develop and produce subassemblies. Such suppliers are often called system suppliers. These suppliers get responsibility for the co-ordination of sub-assembly part suppliers during the design, production, and assembly phases. In this way, a so-called tier structure is built. The system supplier becomes the first-tier supplier, while the part supplier becomes the second-tier supplier.

Besides these developments, clients want their suppliers to be responsible for a sub-assembly to design it 
(in the future) as a module. The difference between a sub-assembly and a module is that a sub-assembly is a composition of parts taken together because of production considerations, while a module has been designed as an integrated whole. Modular design is a design concept that is aimed at robust design of a (part of a) function. A robust design is a design that can be used in more than one version of an end product. To achieve this goal, manufacturers are standardising parts as much as possible. Only specific parts are redesigned. Moreover, in an integrated design redundant functions and over-dimensioning can be prevented. NedCar is an example of a company that has applied the concept of modular design, as can be seen from the following example.

The Volvo X40 (V40 and S40, for example) and the Mitsubishi Carisma are produced on the same platform. This means not only that for both models a number of parts are the same, but also that model specific parts have been designed in such a way that they can be assembled on the same production line. The resemblance between the two types of cars is, hence, larger than the visible resemblance.

From the above we may conclude that tasks and responsibilities shift from clients to suppliers (design task and co-ordination in manufacturing and assembling phase) and that these tasks are changing (modular design).

\subsection{New role of client}

If clients are outsourcing activities, the question of what is the core of the remaining tasks remains. Managers of all companies visited indicated that development, assembly, service and maintenance, and marketing of the end product are viewed as the core activities of the client. The added value of the end producer is its knowledge of the whole product, while suppliers specialise in parts.

In a different phase of the lifecycle of a product, a client will, according to the interviewees, keep on performing the following tasks. The client initiates new projects, based on market research, and performs the concept phase. Its knowledge of the end product as a whole allows it to specify the desired functions. In this task, a client organisation uses its relationships with suppliers to remain informed about new ideas and technologies that may possibly be used.

In the engineering phase, a client co-ordinates its suppliers. It looks after the integration of outsourced systems into one product that satisfies the consumer requirements. For example, consumer requirements on crash and noise performance have to be taken care of by car manufacturers.
After marketing and sales of the product, the consumer will hold the end producer responsible for possible defects. An important task of a client is, hence, to offer service and maintenance to consumers. In performing this task, a client will become more and more dependent on its suppliers.

\section{Changes in selecting clients and suppliers}

Changes in the relationship between clients and suppliers also incorporate changes in developing the relationship. Below, the consequences of the changing relationship for the selection process will be described. First, the selection process of the supplier by the client will be addressed. Second, the selection of clients by suppliers will be described.

\subsection{Selection of suppliers by a client}

A client needs suppliers to perform a product development project. In the course of many years, clients have built a database of suppliers that proved to be suitable candidates. Because of the changing role of suppliers in projects, the current database is no longer suited to support the selection of suppliers. A new database will have to be built.

A large problem, as indicated by the client managers interviewed, is that many suppliers in the current supplier database are not (yet) capable to fulfil their new role. Most suppliers in the database are production specialists for parts (jobbers). The largest part of these suppliers has little experience with design and are surprised by the large number of changes and delays that characterise a design phase. They are not suited as a firsttier system supplier. They will become second-tier suppliers. Since the number of (potential) system suppliers from this group is rather small, clients will have to search for suitable system suppliers outside their current supplier database.

A purchase manager of Océ stressed that selection is not limited to (potential) system suppliers within the same region. The search will incorporate suppliers on a global scale. However, there is preference for system suppliers that are located in the same region because of similarity in culture and distance is smaller. A realistic option is to ask suppliers to build a new company close to the client. NedCar and Polynorm investigate the feasibility of setting up supplier manufacturing facilities on the client site or close to the assembly factories of the client.

Another consequence mentioned in the interviews is the changing role of purchasing. Several engineers indicated that they have been involved in the selection of suppliers that could perform design tasks. However, not only the development department should have been 
involved in the selection of suppliers, but also the purchasing department. Below, an example illustrates this necessity.

One of the companies visited encountered problems, because purchasing was involved at too late a stage. The R\&D department judged suppliers on their suitability to be involved in the design phase. For design, design capability and quality are important aspects. When the purchasing department became informed about the selection of suppliers not all suppliers were judged suitable by the purchasing manager. Some suppliers did not satisfy the criteria that are important during the manufacturing phase, such as delivery reliability and price.

Since relationships are formed for the duration of the whole lifecycle of an end product, all suppliers must be capable of performing all activities required. The purchasing department of the client is traditionally responsible for the selection of and the relationship with the supplier. In this respect, the purchasing task has become important in the selection and maintenance of relationships with suppliers. Purchasers are now relationship managers.

The criteria used by purchasing are no longer focused on short-term collaborative relationships, in which the price criterion played a major role, but on building longterm relationships. Managers are searching for the right criteria. Purchasers are increasingly using audits to judge suppliers on a variety of aspects and to mutually compare them. Several managers indicated that they need a method suited to judge suppliers on their capability to become a system supplier.

To the question whether purchasers need different characteristics a manager replied that they require good relational skills that they have to be able to apply these skills both internally and externally. In addition, he said that a higher education level is needed.

Selection and co-ordination of second-tier suppliers is a new task for system suppliers. This new task requires that system suppliers have to play both the role of supplier to the end manufacturer and the role of the client of the second-tier supplier. A manager of Polynorm realised this fact and indicated that acquiring and building knowledge on purchasing management has become necessary.

\subsection{Selection of clients by supplier}

For a new project, a client, in the person of a purchasing manager, will search for suitable suppliers. A normal procedure in the car manufacturing industry is that a client starts a bid process for a particular order to which suppliers can subscribe. The client asks suppliers to develop a bid in which their ideas and solutions have been formulated. Based on the bids the client will select one supplier.

The selection of bid processes by suppliers can be considered as the selection of clients by suppliers. Since orders in collaborative product development have become strategically important for suppliers, selection of orders for which bids will be prepared have also become strategically important. Consequences of strategic choices, however, are difficult to predict, making the selection process riskier than before.

Engineers and sales managers of Polynorm indicated that the selection process takes longer and investments in time and people are higher, because orders are more complex than before. These changes have consequences. First, the bidding process requires much effort from the people involved, more time, and more means. Furthermore, the investments made not always result in an order, just like before. The time invested and innovative ideas presented are, hence, not always rewarded leading to greater risks for suppliers.

Managers and engineers of Polynorm remarked that most suppliers view this way of working as a long-term investment. They choose to pursue this route. In the bid process a supplier shows its capabilities. Even if a bid does not lead to an order, trust in its expertise and capabilities can be the result, which may eventually lead to orders. Not only long-term orders, but also subscribing to bid processes for those orders, have become strategically important.

Another consequence mentioned is the changing role of sales. One of the sales managers interviewed mentioned some consequences of the changing selection process for sales people. First, sales managers have to negotiate with clients on a higher level. Second, sales people have to put priorities, because the supplier cannot subscribe to all bid processes due to limited resources in terms of time and people. Third, sales managers have to learn to judge the risk involved in bidding.

The following two examples illustrate that judging risk can be very difficult.

Example 1:

A supplier received an order for one part. In the course of the project a second part was added to the first. The supplier proposed to combine these parts into one new part. The client reacted enthusiastically. A new bid process was started. Then, the supplier appeared to be too expensive. The order was given to another supplier. The result was that the supplier lost his order for two parts as well as the one for the new part.

Example 2:

A client defined a bid process for a product large enough to be decomposed into four parts. A supplier 
proposed to use a technology unknown to the client to manufacture the product in two parts. The idea appealed to the client. The supplier received the order.

In the first example, an idea was not rewarded with an order. In the second example it was. Whether the investment by the supplier in the first example will be rewarded in the longer term, for example, because the client observed that the supplier is thinking with the client, is hard to determine.

The question is raised whether the (unpaid) effort clients ask from suppliers is realistic. Collaborative product development involves in principle that a supplier is contracted in a sufficiently early stage to work on the order together with the client. However, from the above it can be observed, that this is not yet always happening.

At the same time, suppliers recognise the need to develop a long-term vision and to convince clients of their capabilities. Managers of Océ and NedCar stressed that suppliers are still too passive in this respect. Sales people still do not approach clients sufficiently proactive. Instead of waiting for the client to come to her, the supplier should present her skills and current developments to the client on a regular basis. Suppliers are still too much focused on gaining orders. In particular, suppliers of mechanical products lag behind in experience and professionalism compared to suppliers of electronics. The supply of mechanical products just started to become important.

A sales manager indicated that sales people should possess good relational skills for their new role similar to purchasers. They must be capable of applying these skills both internally and externally. Similarly, compared to the old role of sales people, the new role requires a higher education level.

\subsection{The changing nature of contracts}

Purchase and sales together close a contract, which formally states a collaborative relationship. According to the purchase and sales managers interviewed, the nature of a contract has changed with the new client-supplier relationship. Relationships are built for a longer period of time. This does not mean that contracts have eternal life or that suppliers will be chosen for new projects automatically. A contract is valid for a particular product and only during the lifecycle of that product. Furthermore, the supplier now has a larger responsibility for the product to be delivered. This responsibility is laid down in the contract as a delivery commitment based on the supplier bid. Depending on her capabilities, the supplier will also request a certain effort from the client. Other contractual arrangements concern delivery times, prices, planning and technical responsibilities.

A problem encountered by several managers and engineers at the clients and customers visited concerns the way responsibility and accountability can be laid down legally. The question is whether this is possible at all. One manager told:

Once we tried to lay down responsibilities, but that appeared very difficult. Discussion took hours and the result was a thick book.

He concluded that this is not a workable situation. In collaboration in product development, he considered most important that all team members, among whom representatives of client and supplier, feel responsible for the project and solve problems together. Another manager confirmed the limited role of contracts:

Basic agreements are made, while partners do not want to spend time on long-lasting negotiations that delay the progress of the process.

Apparently, some risks are hard to cover in contracts. All interviewees stressed that mutual trust in each other's knowledge, skills, and professionalism is a precondition for starting a long-term collaborative relationship.

As has been indicated in the previous section, building trust and reputation costs time, money, and, sometimes, good ideas. Much communication and paying attention to solving problems are important ingredients of this process. Once present and maintained, a good reputation may lead to long-lasting relationships. The experience and knowledge gained in such relationships can be reused to attract new partners.

\section{Changes in the execution of projects}

Changes in relationships also influence the execution of projects contractually arranged between client and supplier. Below, several changes will be discussed, such as (1) changes in tasks, knowledge and skills in product development of supplier and client, respectively, and (2) communication in and alignment of organisations. These two aspects are essential in managing relationships, because they offer possibilities to identify and bridge the differences between the contexts of client and supplier.

\subsection{Tasks, knowledge and skills of supplier}

If current suppliers wish to become first-tier suppliers, they have to build design knowledge and experience. Interviewees of all companies visited view the education of employees and hiring new people as important steps in this direction. The statements of interviewees made clear that product developers (engineers) possess skills that are normally different from those of production engineers who traditionally work in a supplier company 
(jobber). Moreover, engineers often have a higher education level.

In addition, suppliers need a pro-active attitude to become a system supplier. Manager of clients indicated that they are prepared to support the learning process of potential system suppliers. By outsourcing simple projects to suppliers, they can gradually gain experience and design knowledge can be transferred to them. The following example illustrates a possible way to do this.

One of the companies visited stimulates initiatives in which engineers start to work at a supplier on a temporary or even permanent basis. In this way, the supplier builds design knowledge and experience. In addition, the engineer will build knowledge on the culture and way of working of the client thus enabling the building of a strong relationship.

However, clients experienced that guidance and coordination of suppliers cost a lot of time, especially during the engineering phase. It appeared, that building design knowledge takes many years. NedCar has built experience over the past ten years now with outsourcing product development of parts. The step to modular design, in which clients transfer responsibility for a (sub)system to a supplier, has become feasible only now. This development in the car industry illustrates that the desired situation can only be achieved by means of small steps that may take many years.

\subsection{Tasks, responsibilities and skills of clients}

In their new role, clients outsource design tasks to suppliers. A NedCar manager expressed his concern:

The manufacturing organisation will have the problem that she looses knowledge of the design of a subsystem, while she still has to integrate the supplier part in the end product. How can you make sure that the development department, growing smaller because of the outsourcing of design tasks, retains sufficiently detailed knowledge to enable its designer to communicate with suppliers and exert sufficient pressure.

Discussion on the question of which activities and skills belong to the core activities and which don't is still going on. Océ managers indicated that they are still searching for the precise distinction between core and non-core activities.

The co-ordination of tasks has not changed much according to Océ and NedCar managers. The difference is that in earlier days most design activities were performed internally, while now more activities are executed externally. Consequently, less drawers are needed and more employees possessing communicative skills to be able to negotiate with suppliers.

\subsection{Communication becomes essential}

Océ, NedCar, and Polynorm managers and engineers indicated that collaborative product development requires more communication between client and supplier. Communication is not only essential during runtime of a project, but also in the selection process of projects. Since most experiences of interviewees concern the execution phase, communication is discussed in this paragraph.

Interviews at both clients and supplier have revealed that the frequency of personal visits has increased. Apparently, personal contact is important in building trust and dealing with complex problems. Depending on the stage of the engineering cycle (design-build-testredesign, etc.) the frequency of meetings and visits varies from daily to monthly.

Besides personal visits, current ICT offers more and more possibilities to support communication. Companies have experienced that the idea that ICT can replace personal visits (face-to-face communication) is a wrong one. ICT offers merely an extension of the possibilities to exchange information.

An important point mentioned by interviewees in all companies visited concerns openness in the relationship. All relevant information must be exchanged, such as new ideas, problems (both technical and collaborative), and cost structure of products. An often-stated remark was that parties should be discussion partners. One of the engineers remarked:

By being open to other specialists you are working with, knowledge is built on requirements and working areas and all relationships between them. Insight is gained in the reasons why desired changed can be made or not.

Openness has to grow in a team and depends on people liking each other, politics, and power.

Interviews also revealed that the need for intensified communication requires solution of problems. The first problem mentioned is caused by inexperience of managers and engineers with the possibilities of ICT. One engineer indicated, for example, that ICT is insufficiently used in personal visits:

During a meeting at another party, for example in Germany, you wish to encounter and treat all problems that influence your activities. If you discover a problem on the way back, a new appointment has to be made. If drawings were sent via the Internet, you could analyse a design. However, drawings are currently faxed. Drawings in 3D offer more information 
as well as the possibility to discuss technical issues across a distance with the other party.

He suspects that this is not happening, because his company does not yet possess the right software. In addition, the other party is reluctant to exchange information on a subject that is still uncertain.

A second problem with ICT consists of the technical limitations encountered by engineers of the companies visited in collaboration with others. Suppliers, for example, work for more than one client, each of which may have a different system. In the exchange of data between different CAD systems information is often lost. In addition, conversion of data costs a lot of time. To prevent these problems, suppliers, since they increasingly perform design activities, buy the same systems as their clients.

A second problem is, that CAD systems of clients are aimed at supporting the design phase, while CAD systems of suppliers are primarily aimed at supporting the manufacturing phase, in which, for example, CADCAM connection is important. A solution might be integration of CAD systems across the whole product development process. However, technology cannot yet provide such integration.

Finally, the exchange of information via the Internet is indicated to be difficult to secure, causing companies to be reluctant to send information via this route. Managers and engineers are searching for the most effective and efficient combination of communication channels to solve the above-mentioned problems or to get around them. In achieving this, it appears that they are dependent on the possibilities and willingness of the other party.

Besides technical problems, cultural difference might lead to problems in the communication process. Cultural differences may occur on several levels: individual, company, and regional. On the individual level, functional differences between collaborating employees may lead to problems. A production engineer stated:

I work together with product developers who have little knowledge of production. Conversely, production engineers have little knowledge of the functional requirements of which product developers have knowledge. By open communication, mutual insight is gained in each other's discipline. In this way, you can better understand why the other came to a particular decision.

On the company level, cultural differences exist between ways of working. An example illustrates this.

In a meeting, two companies agreed on collaboration in the development of a particular product. In one company, people were used to start the necessary activities based on own initiative. In the other company, a procedure existed stating that first a formal order had to be given before employees can start. As a consequence, both companies were waiting for each other. One company waited for results. The other company waited for a formal order to start.

At the regional level, differences exist in language and norms and values. Employees did, however, not mention language difference as a bottleneck to collaboration. Problems occur, in particular, because of differences in the way people treat each other and deal with specific situations. An example on a problem encountered by one of the Dutch managers may illustrate this.

The decision authority in Japanese organisations is at a higher level in the organisation than in European and American organisations. European and American companies expect that discussion partners have decision authority based on their position in the organisation. At the end of a negotiation, it often appears that the partner has to get approval of his (even) higher boss. This may delay the negotiation process.

All interviewees experienced cultural differences. Solving cultural differences is difficult and often not feasible. One of the interviewees indicated that it is impossible to change the culture of a population. According to all interviewees, knowledge and understanding of the reasons for differences, such as differences in priorities or in approaching situations, are most important.

\subsection{Alignment of organisations is essential}

Communication is difficult when the collaborating partners are not well aligned. The organisations of both client and supplier have to change to enable collaborative product development. In the following section, tasks, responsibilities, and authorities will be discussed that clients and suppliers have assigned to team members. After that, alignment between control processes is described that allow client and supplier to manage project progress.

Teams, both at the client and the supplier, are aimed at executing projects. At the client, teams consist of a project leader, engineers and other specialists, and a purchaser. The project leader is often responsible for a product function part of which is designed internally and part of which externally at a supplier. At many clients, such multi-functional teams are collocated for the duration of a project. At the supplier, teams consist of a project leader, engineers and other specialists (for example production engineers), and a sales person. Since 
these team members take often part in several projects, they are not collocated.

Sales people and purchasers treat commercial affairs like contractual changes. At Polynorm, commercial tasks of the sales person are taken over by a contract manager during the execution phase. This is a new function responsible for unburdening sales people to enable them to focus on the selection of bid processes and developing bids. Engineers, both in client and supplier teams, are responsible for execution of design activities belonging to their specialism. In both teams, the project leader is responsible for the planning of design activities, budgeting, and controlling project progress.

Team members with similar responsibilities are discussion partners. Polynorm engineers indicated that personal contact with employees of the client is one the largest changes in their tasks. Before, only the sales person or purchaser had personal contact with the other party. He discussed both technical and commercial affairs. Now, consultation occurs on all levels of the companies visited.

A problem addressed in one of the companies visited was that in small supplier firms a single person might perform the role of both project leader and engineer. Because of the history of the company, the project leader/engineer is closer to production, which is sometimes the reason for design problems receiving too little attention. The project may encounter delay as a result. This experience indicates, that, if organisations are not aligned communication and, consequently, project progress may be hampered.

A manager of Polynorm mentioned another problem, related to internal alignment of tasks, responsibilities, and authorities. Some clients, he told, are so big that the employees working together hardly know each other. When the internal alignment is not sufficient contradictory decisions might be made. As a consequence, the supplier cannot proceed. By continuous communication with the client, the supplier can play a role in solving and preventing misunderstandings.

Besides the tasks, responsibilities, and authorities of the discussion partners, the control processes must be aligned to guarantee the progress of projects. For the alignment of activities, project leaders make project plans. These plans contain milestones, budgets, evaluation moments and deliverables. In addition, frequency and sometimes themes of formal meetings are planned. To prevent misunderstandings, Océ managers have their suppliers write the project plans. In this way, it can be checked whether both parties have understood each other.

The differences between ways of working and the level of insight into the ways of working of the other party might lead to problems like project delay or budget crossing. An example illustrates this.
A client and her supplier made a first estimate of the hours needed for two phases of a collaborative design project. In this process, differences were observed. For the first phase the estimate of the supplier agreed to the estimate of the client. In the second phase the supplier estimated that she would need about 400 hours. The client advised her to double the amount based on her own experiences. After phase one was finished with a small crossing of the estimated number of hours, the estimate was considered again. Now the supplier expected to need 1200 hours: three times the previous estimate. The reason was that the supplier had estimated the quality level lower than desired by the client, because she had never before worked with that client.

Engineers and managers of all companies visited have experienced that it is necessary to carefully administrate evaluations and the consequent changes in the project plan to prevent unexpected problems occurring. An engineer remarked that a possible reason for insufficient administration is that engineers are used to informing each other about changes informally. Since part of the design activities is performed externally, insufficient administration might cause problems. An example mentioned is budget crossing due to not adapting project plans. To improve co-ordination between client and supplier guidelines have been developed by the engineer.

Other guidelines used by companies to align control processes across company borders are formal (quality) norms. In discussions at NedCar and Polynorm, it appeared that many car manufacturers require first-tier suppliers to be QS9000 certified. For certification, companies must lay down their processes in handbooks. Managers of both companies stressed that this norm does not indicate the real quality level of the processes. Nevertheless, certification provides a NedCar manager with trust in a supplier, rightfully or not, since it looked to its processes.

Noteworthy, there is not always a balance in certification of client and supplier. It happens, that clients require certification of a supplier, while they have not yet been certified themselves. This seems contradictory to the goals of QS9000 certification. Ford, Chrysler, and General Motors have established this norm to improve collaboration between client and supplier in the car industry. QS9000 provides a guideline for configuration of processes and activities. However, alignment can only be realised if supplier and client both adapt their processes.

A manager remarked that for suppliers QS9000 certification would be difficult to achieve, since they collaborate with several, often large, clients which have their own culture and way of working. Standardisation of processes and activities allocated to more than one client will be difficult, even with help of QS9000. 


\section{Conclusions}

Collaborative product development between client and supplier is an answer to stricter market demands. Realisation of the new strategy means transfer of design tasks from clients to suppliers. Collaboration in product development changes the relationship between client and supplier. No longer is one party (often the supplier) subordinated to the other, but all parties are mutually dependent with respect to knowledge, continuity, and care. Clients as well as suppliers will have to change their organisation and adapt to their new role.

Differences between collaborating organisations might cause problems. Managers face the task of understanding these differences and aligning the organisations. Communication is essential to achieve and maintain a balance between client and supplier. On the other hand, communication depends on a well-balanced relationship.

In an empirical study several aspects of management of collaborative product development have been identified, presented in this paper, and again listed below. Further research into management of collaborative product development should be aimed at development of theories and knowledge on the aspects of relationship management. Besides, there is a need for practical means and methods to establish and maintain balance in relationships.

\subsection{Challenges for managers of suppliers}

The largest challenges for managers of collaborative product development at suppliers are:

- Suppliers are not yet sufficiently pro-active in approaching clients;

- Suppliers have too little experience in managing the risks involved in the selection and execution of longterm orders;

- Suppliers have too little knowledge of and experience with design;

- There is too little standardisation in executing activities allocated to more than one client;

- The possibilities of ICT are insufficiently used.

\subsection{Challenges for managers of clients}

The largest challenges for managers of collaborative product development at clients are:

- Clients have still difficulty to determine suitable suppliers;

- The (unpaid) efforts clients request from suppliers seem sometimes unrealistic;

- Clients struggle with the question of which activities to outsource and which to keep, while running the risk of losing strategic knowledge;

- Clients are little aware of the fact that they have to adapt their organisation, just like suppliers;

- The possibilities of ICT are insufficiently used.

\section{Acknowledgements}

The authors thank the companies that participated in this research for the time and effort taken to make the interviews a success.

\section{References}

Douma, M.U., 1997. Strategic alliances: fit or failure. Ph.D. thesis, University of Twente, The Netherlands.

Harrigan, K.R., 1985. Strategies for Joint Ventures. Lexington Books, Lexington, MA.

Helper, S., 1991. How much has really changed between U.S. automakers and their suppliers? Sloan Management Review 32 (4), $15-28$.

Lamming, R., 1996. Squaring lean supply with supply chain management. International Journal of Operations and Production Management 16 (2), 183-196.

Littler, D., Leverick, F., Bruce, M., 1995. Factors affecting the process of collaborative product development: a study of UK manufacturers of information and communications technology products. Journal of Product Innovation Management 12 (1), 16-32.

Quinn, J.B., Hilmer, F.G., 1994. Strategic outsourcing. Sloan Management Review 35 (4), 43-56.

Weenink, S.A.J., 1999. Managing collaborative engineering. Master thesis, University of Twente, Enschede, The Netherlands.

Wognum, P.M., Faber, E.C.C., 1999a. A framework for improving the quality of operation in a virtual enterprise. In: Camarinha-Matos, L.M., Afsarmanesh, H. (Eds.), Infrastructures for Virtual Enterprises. Kluwer, Boston, pp. 365-376.

Wognum, P.M., Faber, E.C.C., 1999b. Duality of integration in collaborative engineering. In: 5th International Conference on Concurrent Enterprising (ICE99), pp. 37-44.

Womack, J.P., Jones, D.T., Roos, D., 1990. The Machine that Changed the World. Rawson Associates, New York.

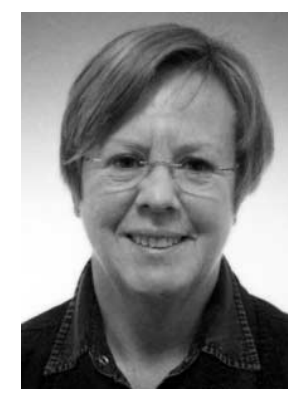

Nel Wognum is Assistant Professor in the Faculty of Technology and Management of the University of Twente in the Netherlands. Her research focuses on collaboration in product development within and between organisations. The goal of the research is to develop methods, tools, and techniques to improve collaboration between people in multi-cultural, multi-disciplinary, multi-functional, and/or multi-site teams. She is a member of the IST Network of Excellence CE-Net (Concurrent Enterprising Network). 


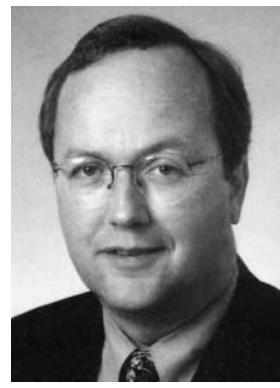

Olaf Fisscher is Professor of Quality Management and Business Ethics in the Faculty of Technology and Management of the University of Twente in the Netherlands. His area of research focuses on responsible management in innovation processes. He is also Head of the Department of Technology and Organisation. Olaf Fisscher is the author of many articles and books on organisational values, quality management and management of technology and innovation.

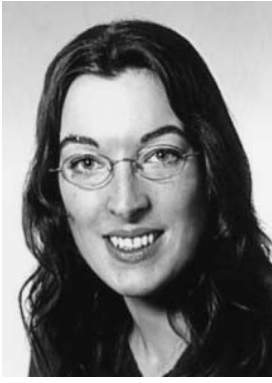

Suzanne Weenink is currently employed at Polynorm Automotive BV in Bunschoten as a co-ordinator of the programme to set-up a new press shop in Brazil. She has been involved in the research reported in the paper as a temporary Research Assistant. The research has been a continuation of her Master thesis work. 